\title{
Time as a Hidden Curriculum: Qualitative Study of Challenges Faced by Students with Mobility, Speech, and Visual Disabilities in P-12 Settings \\ Theodoto W. Ressa ${ }^{1}$, Derek E. Daniels², Sheri Wells-Jensen ${ }^{3}$
}

Article History:

Received 16.09.2020

Received in revised form

25.04.2021

Accepted

Available online 01.07.2021

\begin{abstract}
Formal education is schedule driven yet time as a hidden curriculum pertaining to students with disabilities is understudied. The authors share different challenges around disability: The first author has a physical disability and is a wheelchair user and teaches disability and equity studies in education, the second author stutters and teaches speechlanguage pathology, and the third author is blind and is a white cane user and teaches linguistic and disability courses. Informed by personal and educational disability experiences, the authors examine three case scenarios related to the schooling of learners with mobility, speech, and visual disabilities in P-12 settings to understand the interaction of time and curriculum and the impact on their education. Since time as a hidden curriculum can be a barrier for students with physical, speech, and visual disabilities, then there is a need for the reconceptualization of time within the frame of curriculum development to genuinely support the schooling of students with disabilities.
\end{abstract}

(C) IJERE. All rights reserved

Keywords: ${ }^{4}$

Disability, education, time, hidden curriculum, discrimination

\section{INTRODUCTION}

Curriculum is a guideline and a basis of what will be taught to students based on age, subject area, grade level, and state and national or international standards for the purpose of gaining substantive experiences (Berg et al., 2017; McLean \& Dixit, 2018). Unlike informal curriculum that supports acquisition of repertories in unstructured environments, formal curriculum dictates learning in a more structured environments and learning activities and events (e.g., in specific buildings and time) (Nelms, 1991). The structure of formal schooling means that students participate in more organized learning activities and events at a specific location and time for a purpose of achieving goals deemed significant to the society but often decided upon by a few experts (e.g., curricula developers - educators, policy makers). Within formal schooling are many unacknowledged but influential happenings that impact learning outcomes - the hidden curriculum (About Education, 2016). Hidden curriculum is an implicit learning and development practices (e.g., classroom discourse, academic writing, classroom norms) that influence teacher-student relationships, teaching and learning processes, and therefore student's learning outcomes and future life (Berg et al., 2017). These unplanned or implicit learning process determine students growth and development and adulthood quality of life (Giroux \& Penna, 1979). The consequences of implicit learning processes often are detrimental to schooling of learners with disabilities; often they lead to segregation, low expectation, denial of supports, low performance, school dropout, unachieved postschool outcomes, and low quality of life in adulthood (Danforth, 2017).

Considering the impact of hidden curriculum on students' education, the authors are interested in mapping the schooling of learners with special needs relative to time as a hidden curriculum. The first author has a physical disability and is a wheelchair user and teaches disability and equity studies in education, the second author stutters and teaches speech-language pathology, and the third author is blind and is a white cane user and teaches linguistic and disability courses. The authors of this paper all share different challenges around disability, but one common denominator we have found worthy of exploration is time-the ways in which time can be challenging for us and how we navigate these challenges. In this paper, we reflect upon time as a hidden curriculum for our respective disability identities (mobility, speech, and visual) and the ways it can impact students from pre-kindergarten through twelfth grade $(\mathrm{P}-12)$ based on United States education system. Our goal is to identify critical curriculum components related to time so we can help teachers, faculty, and professionals to implement appropriate mechanisms that enhance their institutions' curriculum and settings, preparing students with disabilities for successful adulthood both in terms of academics and future careers. We are interested in how time as a hidden curriculum is or is not perpetuated in learning institutions and how it informs competency judgments of students with disabilities. Our guiding research question is as

\footnotetext{
${ }^{1}$ theodoto@hotmail.com, https://orcid.org/0000-0003-4599-921X, Division of Teacher Education Wayne State University, USA.

2 dedaniels@wayne.edu, Department of Communication Sciences and Disorders, Wayne State University, USA.

${ }^{3}$ swellsj@bgsu.edu, Department of English, Bowling Green State University, Bowling Green, USA
} 
follows: How does time as a hidden curriculum impact the education of learners with mobility, stuttering, and visual disabilities?.

There is no single correct definition of time because of its multiple features, different schools of thought (e.g., science, philosophy, religion) (Carroll, 2009), and different disciplines (e.g., art, music, science, humanities, business, sports, industry) (Zeigler, 2008). Broadly, time is conceptualized as an experience, an event, and a measuring instrument. Based on its attributes, time can be defined as an indefinite period marked by specific activities and events occurring in an irretrievable series from past to present to future. Time is quantitative and qualitative, objective and subjective, relative and relational, flexible and absolute, abstract and concrete, real and ideal, tangible and intangible, material and immaterial, intellectual and non-intellectual, constant and dynamic (Carroll, 2010; Luckham \& Schulte, 2011; Núñez, 2012). Time as an element of a measurement quantity allows for the examination and understanding of (im)material things in terms of rate, frequency, duration, and intensity (Ivey \& Hume, 1974; Le Poidevin, 2004; Zeigler, 2008). Through these elements, it enables the subjectifying and objectifying of material and immaterial things and judging real and ideal materials relative to human experiences (McRuer, 2017; Samuels, 2017).

There are different schools of thought about time. Time is generally believed to be either relative or relational (Núñez et al., 2012; St. Augustine, 2012). Relative time, as physicists frame it, helps humans to understand experiences by measuring mobile objects based on the passage of matter (e.g., moon, sun, or stars). Physics has operationalized time to mean reading by a timepiece showing a period and its events/activities (Burnham, 2006; Considine \& Considine, 1985). Here, the tools used to quantify time measurement include clocks and calendars.

In contrast, relational time occurs when objects interact, one example being teachers and students in a classroom (Bunnag, 2017; Kant, 2004). Use of time is closely related to time management and time discipline (Elias, 1992; Russell, 1987). Time management refers to using tools (e.g., calendars, day planners) to organize activities and events into an actable process. Time discipline is the adherence to a community's rules and procedures. In sociology and anthropology, time is associated with the laws, customs, and rituals governing human interactions and activities within the social, political, economic, cultural, and linguistic domains. Although understudied, time use is equally central in education, where it has great influence on student-teacher and peer-peer interactions, relations, learning processes, and outcomes. Time plays a critical role in sequencing events and relation-building. Activities and events are arranged such that a cause leads to an effect (e.g., quantity and quality teaching lead to the quantity and quality learning of a concept) (Luckham \& Schulte, 2011); they are also arranged to allow humans to tell stories (Nordquist, 2011), narrate their experiences, conceptualize directions, provide people tasks or procedures (Piasecki, 2011), and understand spaces (Núñez et al., 2012).

There is a connection between time, space, and mind-thinking about and organizing events, activities, and space occurs in the mind (Núñez et al., 2012). Time's spatial representation is often referred to as a mental timeline (MTL) (Bottini et al., 2015). Here, time is not a substance but a mental configuration that helps humans to experience the world. These experiences make time an intellectual concept, especially when it informs judgment of people's behaviors and emotions (e.g., comparing students' abilities as fast/slow, diligent/lazy, punctual/tardy, intelligent/stupid, patient/impatient, friendly/unfriendly) (Fialka, 2016; McRuer, 2017; Samuels, 2017).

Time and space, as well as time and culture, are entwined (Bottini et al., 2015). Time influences how space is used and vice versa - these associations also influence human interactions, judgments, and relations. Similarly, time and culture are used to determine social communications, relationships, and communitybuilding. Cultures influence how humans organize places, spaces, and time events in the past, present, and future; thus, our interactions and relations tend to be informed by our individual orientations toward our environments (Núñez et al., 2012).

Time can lead to harmonizing cultures and personal success or clashing cultures and individual failure. Conceptualizing time, space, and culture has mostly worked against students with disabilities. Abstract and concrete thinking about disability have contributed to a clash of time culture, which has made educating students with disabilities an uncertain exercise (Núñez et al., 2012). Time creates structure and balance, but for students with disabilities, time, space, and culture can serve as barriers when changes influence sequencing activities, events, and how people orient themselves. To illustrate, the belief that 
disability is an unnatural individual burdensome experience is a cyclical structure of the past, present, and future. This time-informed meaning-making of disability is the basis of disability-based discrimination in schools. Thus, exploring time as a hidden curriculum is vital to understanding education's impact on learners with disabilities.

Curriculum has been defined in a number of ways, but most consider it to comprise the courses that learning institutions offer. It is a plan for education that provides the structure and scope of an educational program for learners (Nelms, 1991). A curriculum is the subjects and lessons explicitly taught in the classroom (McLean \& Dixit, 2018). Different information or lessons taught informally or formally by parents, families, friends, and teachers also constitute a curriculum. Informal education has less structured settings and lessons - here, students participate in less organized locations with less organized but still rigorous lessons. In this context, experiential learning (i.e., learning by doing) is geared toward learners' immediate worlds and community needs. For example, the traditional learning of cattle rearing in the villages in Africa or learning how to ride a bicycle. Conversely, formal education has more structured settings and lessons. Students participate in more organized locations with more organized activities and events, and their learning activities address their needs at a specific level (i.e., grade) in a specific area (i.e., subject, skills, knowledge) at a specific location (i.e., physical or digital school).

The hidden curriculum is the ". . unspoken and unacknowledged content and skills that supports academic and adult-level performance" (About Education, 2016; cited in Berg et al., 2017, p. 2). Berg et al. (2017) simply and broadly describe the hidden curriculum by supposing it includes covert learning and development practices. This means practices such as cues and discourses teachers employ in lesson delivery or interaction and communication with students and colleagues while imparting the formal curriculum. Scholars consider the hidden curriculum to be the unintended learning process created by learners' school culture and environment that influences their growth and development (i.e., acquisition of experiences, knowledge, and skills) (Berg et al., 2017; Giroux \& Penna, 1979). Unintended learning processes may involve practices such as notetaking, raising your hand before asking a question, sitting still unless the teacher calls on you, bringing certain books to class, or considering some learning materials appropriate for a lesson and others inappropriate (e.g., books but not a laptop). Though not explicitly stated, students discern these learning processes and practices through contextual socialization and orientation. Thus, the hidden curriculum's impact is considerably influenced by prolonged exposure and time.

\section{METHOD}

In order to answer the research question on the impact of time as a hidden curriculum, a qualitative research was used to elucidate the complex interactions teachers, learners with disabilities, and the curriculum within and without the schooling environments (Corbin \& Strauss, 2008). Teaching and learning and curriculum and time are both art and science related activities and events but also material and immaterial factors. These qualities make qualitative research approach suitable in contextualizing how learning processes of students with disabilities are influenced by time and curriculum and hidden curriculum (Bernard, 2017; Castillo et al., 2016). For centuries schooling of students with disabilities around the world has remained low in comparison to students without disabilities (Danforth, 2017). This educational discrepancy is sustained by many factors often packaged in the curricula but often unknown to many stakeholders in education (Berg et al., 2017). Therefore, qualitative research methods enabled authors to reflect on their schooling and to use their worldview to assess their P-12 learning environments, to identify circumstances that influenced their schooling, and to describe factors that continue to impact education of students with physical disability, speech disability (Palinkas et al., 2011; Patton, 2014; Teddlie \& Tashakkori, 2003). Next are our case scenarios.

\section{Case Scenarios of Time as a Hidden Curriculum}

Disability prevalence in U.S. P-12 level public schools is about 13\% (Lauer et al., 2018) and in 2018, about 7.1 million children aged 3-21 received special education services under the Individuals with Disabilities Education Act (IDEA) of 2004 (U.S. Department of Education, n.d.), which included children with physical, speech, and visual impairments. While many children need specialized support, disability awareness remains remote, and service and resource provision remain inadequate despite anti-discrimination disability laws (Section 504 of the Rehabilitation Act 1973; Americans with Disabilities Act 1990; IDEA, 2004). Therefore, these young populations are most likely to experience environmental challenges that adversely impact major life 
activities like receiving an education and pursuing a career (Okoro et al., 2018). The following case scenarios of students with physical, speech, and visual disabilities are informed by the authors' personal experiences and describe moments of time as a hidden curriculum in P-12.

\section{Maxwell-A Student with a Physical Disability}

First author shares schooling experiences of Maxwell (pseudonym), a fifth grader at Flowerbed Elementary School who uses an electric wheelchair. Today, Maxwell discovers that the male restroom on the main floor, while supposedly accessible, has corners his wheelchair cannot navigate. So, he backs into the main hallway and takes the elevator to the basement and the only accessible bathroom in the four-story school building. Here, two regular stalls are empty, and a non-wheelchair user occupies the only accessible stall. Unfortunately, the two empty stalls are too narrow for Maxwell's wheelchair to get into.

He waits patiently, hoping the other person will be done quickly. Three minutes pass, with no signs the occupant plans to leave; he is absorbed in a conversation and laughs intermittently. Meanwhile, Maxwell struggles to control his bladder, still hoping the other occupant will exit soon. Now a minute seems more protracted, and he swivels on his chair to distract his bladder so he does not have an accident.

The other occupant is apparently on a long call. So instead of wetting himself, Maxwell tries to get into an empty stall. He wheels close to the door opening and makes a 45-degree angle so part of the wheelchair is inside the stall, and then pushes himself off it. With a single step, he lands with a thud on the toilet seat, where toilet water splashes on his pants. "Ouch! Stinks!" He cries aloud. After relieving himself, he struggles up and finally manages to transfer himself back to his wheelchair. His neighbor in the accessible stall seems to be calling different people on the phone. Maxwell wheels to the sink and thoroughly washes his hands, then grabs a paper towel, wets it with soap and scrubs his pants where the toilet water splashed him. He manages to reduce the stench after five attempts. Meanwhile, he notices numbness and tingling in his hands and fingers. He thinks it is because of the compression during the fall on the toilet seat and tight grips he had to have on objects as he transferred himself from his wheelchair to the toilet seat and back. He hoped he did not damage any of the nerves in his arms or wrists.

He pushes the accessible button to open the bathroom door, rushes out, and rides the elevator to the third floor, where his afternoon class is already 15 minutes in. Mr. John, the science teacher, hands him a three-page worksheet and continues the lesson. Maxwell is lost but does not want to interrupt the teacher. He reaches for his bag at the back of the wheelchair and feels some tingling in his left hand and numbness in his right fingers. He struggles to hold his pen. It falls on the floor. A nearby student picks it up and hands it to him. It accidentally falls again, but the student maintains her gaze on the teacher. Behind him, two peers stare at him intently, making him nervous. "Is it the stench?" He is embarrassed. After two minutes, he wheels out of class; Mr. John smiles with a grimace, which makes some students smirk.

As shown above, the time spent navigating physical and mental spaces greatly affects Maxwell's academic and relational challenges but is not factored into his learning. Maxwell misses the first portion of his lesson. While the teacher provides him with the three-page worksheet as soon as he arrives, he is not oriented toward the lesson material. The teacher continues with the lesson uninterruptedly rather than spending time acclimatizing Maxwell to the class and learning activities; this is probably because he, for the sake of time, wants to get through the lesson and achieve the lesson objectives with the rest of the class. The teacher's focus and effort toward the whole class instead of an individual learner means he does little to include Maxwell in the immediate learning events.

Maxwell becomes the center of attention when his pen falls off the table because of the difficulty he has holding it with his fingers after possibly damaging his hands during the bathroom accident. However, his classmate's attention (the student who picks up the pen from the floor once but does not do so when it falls again) makes him feel bothersome and guilty of his difference. Conscious of his situation, he also suspects and worries that his classmates' curiosity is caused by the foul smell from his clothes. His uneasiness causes him to wheel out of the class, which again leads to derisive behaviors from the class (i.e., the teacher's smiles and grimaces and his classmates' chuckles and smirks). Unfortunately, the teacher's behavior inadvertently communicated to Maxwell that he values the class over him, adding to his tension and causing him to leave the class in the middle of the lesson. Such thoughts about whether the teacher cares about him or not may have caused him to question whether he is welcome or even belongs in this space. Consequently, his involvement in the lesson and likely future learning is ruined by a cascade of time-related events that make Maxwell feel guilty of himself, feel unwelcomed, and feel like he does not belong. 
Self-guilt, peer curiosity or concern, and his teacher's effort and/or disinterest in him/what happened made Maxwell suspicious, nervous, uncomfortable, and distrustful of his classmates (even though they were positively concerned and supportive, as shown by the student who picked up his pen). Nonetheless, the events in the classroom unsettle Maxwell, and the resultant cognitive dissonance causes learning interruptions and confusions. Unfortunately, Maxwell's teachers are more likely to underestimate him and hold lower expectations for his performance, capping his learning potential. However, when provided with an appropriate learning environment that enhances his functionality (e.g., an accessible bathroom on the third floor), Maxwell would have ample time, like his peers without disabilities, to adequately prepare for class. Thus, the ripple effect of inaccessible bathroom on the third floor, which is directly connected to time and indirectly to the curriculum, upsets Maxwell's schooling just because it requires a considerable amount of time to use the bathroom, which although important is not significantly factored in his mobility and education.

\section{Joel-A Student with a Stuttering Disability}

Second author shares schooling experiences of Joel, a seventh grader at Oakland Middle School. Joel likes soccer and mathematics, but he performs above average in all subjects. At 9:30 am, Joel has a history lesson. Not his favorite subject, but he enjoyed reading the WWII chapter assigned two weeks earlier. Every student is required to annotate and share important points with peers. Everything starts in time and high intensity, with the teacher timing the presentations and directing the discussion. Joel is eager to share his two and a half pages of notes when his turn comes.

He starts reading the first paragraph, then suddenly begins repeating the consonant "K." After about 30 seconds, he continues reading but again gets stuck at "T." He clenches his fist as he tries to say the word, taking another few seconds. The teacher is now uneasy and asks, "Joel, are you OK?" Some students briefly laugh, making the teacher giggle. The teacher then says with exasperation, "We'll have to move on for the sake of time. Class, you can make an appointment with Joel to discuss his findings. Next, Alexandria." After Alexandria presents her points, the teacher remarks, "Excellent!"

As shown above, students who stutter receive little learning support. Joel is a brilliant boy and a stutterer who repeats sounds within words, experiences prolonged sounds, and get stuck on sounds, especially "K" and "T." These cause unwelcome and unsupportive attention from his classmates. Though prepared for the morning history lesson and enthusiastic to share his research findings with the whole class, Joel's stuttering causes his teacher to become impatient and his peers to mock him. He is made more uncomfortable when the teacher cuts him off and calls on the next presenter, later providing positive reinforcement to her. Un/intentional lack of acknowledgement of Joel's effort add to the traumatizing experience when his peers and teacher covertly frame his stuttering as not knowing the WWII content. Such framing, however, implants confusion or self-doubt in Joel's mind and implicitly communicates to the whole class that Joel is inadequate and different from his nondisabled peers. The teacher's impatience because of lack of time also fosters an impolite attitude in Joel's nondisabled peers. Such negative attitudes toward stutterers predispose Joel to stuttering triggers, creating a cyclical problem that impedes his relationship with his peers and teacher and therefore his participation in learning.

\section{Juliette-A Student with a Visual Disability}

Third author shares schooling experiences of Juliette, a 16-year-old tenth grader at Grassroot High School. Juliette is blind and normally travels with a folding white cane. However, the crowding in the hallways between classes sometimes makes it necessary for her to shorten her grip on the cane, reducing both her walking speed and sense of security. She has tried leaving class early to avoid the crowds, but she is uncomfortable with the extra attention this causes. Still, the noise and confusion in the hallways between classes slows her considerably, and she is sometimes late for classes if they are far apart in the building.

Juliette is proficient in braille, but she often does not receive classroom material at the same time as the rest of her classmates because it has to be converted into braille. This makes it hard for her to follow what is going on in some classes, causing her to have to choose between turning in incomplete or inaccurate work on time and turning work in late.

In the lunchroom, she is quite capable of getting her own food and finding a place to sit, but she must take the time to stop and listen to the people moving around her to plan her route. Impatient students and faculty sometimes grab her and push or pull her in the direction they think she wants to go. In the food line, she does not have access to the printed menu, so she must either take the time to ask what the dishes are or allow a cafeteria worker to put dishes on her tray without much explanation. 
Juliette auditioned for choir, but when the director saw her carefully exploring the risers to find her place, he decided choir was "too dangerous" and asked that she either arrive early to choir so he could "help her find her place" or choose another class. Biology is her favorite subject, but since she does not have direct access to the many diagrams and pictures, she falls behind in her coursework. Because of this, the teacher has not allowed her to partner with the student she wanted to. Instead, the teacher gave Juliette two lab partners who have been told to "help her" with the material. Reluctant to slow the group by asking questions, Juliette has become largely passive during class. She does well on tests because she has access to the textbook, but she feels excluded and discouraged and has decided not to take senior biology next year. In the spring semester, Juliette and a friend both tried out for and made the track team. Juliette is a reasonably fast runner, but before each away meet, she and her friend took extra time to orient her to the facility. When Juliette's friend dropped out of track, Juliette did too.

As shown above, Juliette receives some accommodations at her school. For instance, she has an accommodation to leave the class early to avoid crowding in the hallways and to get to classes on time, especially when they are located far apart. However, this accommodation has negative effects on her learning. Often, she gets distracted as she prepares to leave the class early enough and misses a lot of important points during lesson recapitulation. Further, she worries that leaving class early attracts unnecessary troubling class attention to her. Personal challenges usually entwine with academic difficulties in ways that negatively affect educational outcomes. For instance, Juliette is proficient in Braille, but many times, she does not receive learning materials in Braille in a timely manner, thus creating a time lag in her learning. Juliette's teachers and peers are always ready to guide her in the right direction. Unfortunately, due to ignorance about blind people's orientation to their settings, Juliette is occasionally infantilized when her peers and teachers grab her by the hand. While it sounds like she is in a supportive setting, Juliette must put a lot of effort into her schooling because time as a hidden curriculum makes it difficult to reconcile her personal qualities with the structured school environment.

\section{DISCUSSION}

We now analyze time as a hidden curriculum and the impact it has on the education of students who embody different abilities. The case scenarios illustrate the experiences of students with physical, communication, and visual disabilities in their quest for education and how time as a hidden curriculum influences their inclusion in different learning activities and environments. These stories describe ordinary experiences with time-induced barriers that are often invisible to nondisabled people. Such time barriers encourage noticeable practices of discrimination against students with disabilities, impeding their learning, causing low (academic) performance, exclusion, and an eventual low quality of life in adulthood. The successes of students with disabilities are associated with the time, space, and culture of an institution, and so below we focus on each case scenarios to understand how time as a hidden curriculum manifests differently through these students.

\section{Learners with Different Physical and Mobility Statuses}

The category of mobility impairment encompasses congenital or acquired anomalies that are temporary or permanent, stable or progressive, visible or invisible (Silvestri, 2018) because they are caused by a variety of factors (e.g., lead poisoning, trauma, maldevelopment [e.g., spina bifida], diseases [e.g., cancer, tuberculosis, COVID-19, juvenile arthritis, asthma], and/or weak body organs [e.g., weak fingers to grip pencil]) (Ameringer et al., 2012; Eisenstein, 2016; Nogrady, 2014; Oppenheimer et al., 2018; Thompson \& Gustafson, 1996). The anomalies affect ambulation, muscle bulk, tone, strength, vitality, or alertness (IDEA, 2004; Kang, 2019). Specifically, learners with physical impairments have health conditions that limit autonomous, self-directed, meaningful physical movement of the whole or part of the body due to damage to neuromuscular and musculoskeletal systems; this affects performance of ambulation, gait, posture, sitting, standing, climbing or holding (Silvestri, 2018). Students may experience pain, discomfort, depression, or anxiety (Shiu, 2001); may need frequent medications, the side effects of which may impair cognitive and perceptual abilities; or may require frequent rest (Linton et al., 2018; Paturel, 2015). Others may experience losses in sensory capacities (i.e., sight, hearing, taste, touch, smell, and language and speaking ability), have low muscle mass and strength, have stiff joints and spasticity, have limited ranges of motion, have limited coordination and manual dexterity, and have defective gaits (Kang, 2019). Other students may also experience food restrictions, especially those who are allergic to peanuts, for example (Shiu, 2001). Any limitation of motion of the body impacts educational outcomes (Kang, 2019), as could be seen in the case of Maxwell. 
Teachers habitually fail to consider how mobility limitations impact learners, for example, how wheeling between places or manipulating doors, books, or computers are effort and time-related processes that are not correlated with a child's cognitive abilities. Still, often, abilities-especially the intelligence of learners with disabilities - are measured using formal and informal instruments such as the Wechsler intelligence scale, task analysis, or regular graded/ungraded-but-judgmental class tests (Bottge et al., 2020). The need to navigate and act within prescribed times and structures creates demands that may overwhelm students with mobility issues. Time for self-care (e.g., using bathroom) is intricately tied to students' participation in learning activities, interactions with teachers, and socialization with peers.

Time, then, is critical in shaping both how students with mobility disabilities see themselves and how nondisabled children and adults see them. Positive teacher and student views will likely create an inclusive climate, supporting the students' self-esteem and enhancing their feeling of belonging. Environments with opportunities help students with mobility disabilities grow and develop. While academic failures often stem from correctable factors linked to time, the blame for said failure is often individualized, with educators focusing on the student's impairment rather than on inaccessible learning materials or settings, thus making life of students with mobility issues difficult. Considering academic failure of students with mobility issues outside the context of the myriad causal elements, teachers might depersonalize them, and based on misjudging who they are, conclude that they are incapable of functioning in general classrooms. Such conclusions can contribute to social and physical divides, qualifying and justifying the oppression of learners with mobility issues.

\section{Learners with Speech and Stuttering Statuses}

Speaking is a complex motor activity that communicates thoughts and feelings and conveys a sense of who we are. Oral speech requires complex coordination of breathing, voicing, and articulation that results in smooth and meaningful verbal output. Speech impairment occurs when a certain speech component presents as faulty. The variety of speech impairments include speech sound disorders, verbal apraxia of speech, dysarthria, and voice disorders (Fogle, 2019). Stuttering happens when the flow and rhythm of speech are interrupted. People who stutter may repeat sounds or syllables within words, repeat whole words, prolong sounds, or get stuck on sounds. These speech disruptions may lead to the person experiencing adverse thoughts, feelings, and reactions toward talking.

School is a significant context for those involved; unfortunately, both students and adults can experience negative psychosocial experiences around stuttering-particularly relating to the concept of time-in the school context (Crichton-Smith, 2002; Daniels et al., 2012; Franck et al., 2003; Klompas \& Ross, 2004). Daniels et al. (2012) found that when participants retrospectively discussed their school experiences, themes such as classroom participation (e.g., oral reading, oral presentations, responding to questions), teacher and peer interactions, and academics and learning emerged as having been difficult. These themes center around time as a hidden curriculum, where people who stutter indirectly receive messages that fluency, speed, and efficiency determine what is acceptable in speaking. Crowe and Walton (1981) assessed the attitudes of 100 elementary school teachers working in a Mississippi school district toward stuttering using an inventory on attitudes toward stuttering and a stuttering knowledge test. The authors discovered that a positive correlation existed between attitudes toward stuttering and knowledge of stuttering (more positive attitudes correlated with increased knowledge). A negative correlation existed between attitudes toward stuttering and whether the teacher had a student who stuttered in class (i.e., teachers with more desirable attitudes were less likely to have a student who stuttered). Yeakle and Cooper (1986) surveyed 521 schoolteachers in a school district (82\% of the district's total teachers) in Alabama to explore perceptions of stuttering. Approximately half (48.5\%) taught grades $\mathrm{K}-6$, and $41.9 \%$ taught grades $7-12$. The remaining $9.6 \%$ taught either preschool children or adults. The survey questions sampled perceptions of stuttering etiology, the impact of stuttering on the people who stutter, the personality characteristics of people who stutter, and teacher responses to people who stutter in classrooms. Teachers who were more knowledgeable about stuttering, took courses on stuttering, or had taught students who stuttered expressed more favorable attitudes toward people who stuttered and had positive expectations of people who stuttered in the classroom.

Other studies also confirm that educators can have negative perceptions of learners who stutter. Lass et al. (1992) surveyed 103 teachers in school systems across five states to explore perceptions toward people who stutter. The participants listed adjectives describing four hypothetical people who stuttered: a typical eightyear-old female and eight-year-old male and a typical adult female and adult male. The schoolteachers 
described the four people as "shy," "insecure," and "nervous." Most of the negative adjectives focused on personality traits rather than appearance, intelligence, or speech. Silverman and Marik (1993) replicated this study with 58 schoolteachers in Wisconsin, likewise revealing that schoolteachers tended to view people who stutter as shy, quiet, nervous, insecure, frustrated, anxious, and self-conscious. Lass et al. (1994) explored the perceptions of 42 school administrators-principals, assistant principals, superintendents, assistant superintendents, special education coordinators, and elementary education supervisors - toward people who stuttered. These administrators listed adjectives describing four hypothetical persons who stuttered: a male child, a female child, a male adult, and a female adult. The administrators listed many negative adjectives such as "shy," "quiet," and "nervous". However, while these traits may be classified as negative, one cannot assume that the schoolteachers and administrators hold negative stereotypes that are harmful to people who stutter; these adjectives may simply reflect the reality of how people who stutter behave in classroom settings.

Although people who stutter are subject to negative perceptions and stereotypes by school educators, research suggests they also encounter such perceptions from peers (Davis et al., 2002; Franck et al., 2003; HughJones \& Smith, 1999). Frank et al. (2003) explored the perceptions of four groups of fourth- and fifth-grade students toward peers who stuttered. Each group viewed a videotape of a speaker either stuttering or not stuttering while reading a poem and rated the speaker's intelligence and personality traits. The participants held more negative views of the person who stuttered, as evidenced in the lower mean ratings on an administered adjective scale and the observed participants' informal behaviors (e.g., laughing, insensitive comments) when viewing the videotape. These negative perceptions are also evidenced in the bullying by peers that people who stutter experience (Davis et al., 2002; Hugh-Jones \& Smith, 1999).

Stutterers experience difficulties with friendships, bullying, and theft of personal things (e.g., books) (Hugh-Jones \& Smith, 1999). While some teachers and parents take actions to prevent bullying of people who stutter, unfortunately, many times teachers and parents are never aware of the bullying and situations where they are aware often they do not take measures to prevent it. Unfortunately, teachers and peers' negative view of stuttering hinders student-teacher and student-classmate relationships and negatively affect their emotional status and academic performance (Klompas \& Ross, 2004).

\section{Learners with Visual Disability Statuses}

Popular media encourages the idea that blindness is binary-a person is either blind (i.e., completely unable to see) or is not blind (able to see). In reality, visual impairment is a continuum, from those using glasses or contacts to compensate for slight vision imperfection to those who (although still able to see) are considered "legally blind" to those that are blind (i.e., cannot see at all) (Lennie \& Van Hemel, 2002; The Vision Council, 2015). Legal blindness marks the point where generic "bad vision" becomes systematically problematic-a barrier to completing ordinary tasks or making social or work obligations difficult without adaptive techniques (e.g., using lenses or glasses or white canes) (Black, 2017). Accommodations can be provided at work and school upon reaching this arbitrary line, currently set in the US at less than 20/200 vision in the better eye with correction or a visual field of less than 20 degrees (Ray et al., 2016). Since most blind people are at the top of this range, the overwhelming majority identifying as blind or visually impaired have some useable vision, with only $10 \%$ of individuals being fully blind-lacking, or almost lacking, the ability to perceive light (Gabbert, 2012). Thus, some blind students may require extra lighting to use their residual vision, whereas others may have acute light sensitivity and need to block light with dark glasses or avoid bright lights altogether. Although few people are fully blind, people with visual impairments always work in non-visual ways - many legally blind people use faster and easier non-visual techniques (e.g., trailing, push-toys) rather than relying on vision.

Time and information are crucially linked and affect the blind and sighted people differently. Information is given in time and takes time to absorb, and visual access to information is not always faster. For example, if a blind and a sighted child search for something (e.g., pen), the sighted child will find the object first if it is left in the middle of the floor, but the blind child may find it more quickly if it is on the couch under a blanket. Still, visual information flow often tends to parallel simultaneously available details, whereas some kinds of nonvisual information are acquired serially through language or systematic exploration. Information about a room layout or an object's location is instantly accessible visually. A sighted student views a classroom and instantly incorporates chair layouts, determines which end of the room is the front, and grasps the position of the doors and windows. A blind child could be told this information, or they could explore the territory on their own, making a mental map. Both describing and exploring are good ways to understand one's 
environment, and both take time. Similarly, while sighted students learn their way to the classroom, lunchroom, and around the playground without conscious thought, the blind child will explore systematically, gathering the same information sequentially.

Similar kinds of time-intensive exploration occur in paper-based tasks. Visual readers with access to a printed page readily locate titles, italicized texts, or key words. These tasks are different for a Braille reader exploring a page by touch and for a large print reader who may need to access the page in smaller sections. In both cases, material easily found or even self-evident to the sighted reader will take time to uncover using alternative techniques. Similarly, when sighted students are finished with an object, they may set it aside. When they need it again, its location is obvious, and they directly pick it up. Blind students will find the object by touch. Neither type of student remembers its exact location, but the process of relocating it is instantaneous for sighted students and a matter of momentary exploration for blind students. Neither technique is better or more accurate-both types of student find what they need, but blind students use more time.

If an object is dropped, sighted students glance down, locate it visually, and retrieve it. blind students, noting the sound the object makes, have a good idea where to begin but will locate it through systematic exploration. Again, neither approach is superior, as both succeed in retrieving the object, but blind students may use more time than sighted students. This normal, adaptive, responsible seeking behavior is often interrupted by an impatient aid or teacher who misinterprets exploration as ignorance. Time is the essential element to blind students' learning - time to explore and to organize gathered information. Rushing them to stay in lockstep with their sighted peers effectively short-circuits their learning, leaving them in a position of being given information without the opportunity to learn for themselves.

\section{Enabling Time in the Curricula to Successful Schooling}

The three case scenarios reveal that when disability statuses are not factored into teaching and learning, time creates inappropriate hidden curriculum messages. Speed and acceleration are crucial curriculum elements because schooling activities and events all revolve around schedules that inform how stakeholders in education (e.g., teachers, administrators, politicians) judge students' competency and the statuses they are assigned-typical or special needs, for example. Often, educators enact time as a hidden curriculum when they privilege time-related practices that manipulate and tailor the curriculum to best serve students without disabilities. As in the three case scenarios, time causes educators to be inconsiderate to the learning needs of their students with mobility, speech, and visual disabilities. Educators who are unaware that time-oriented learning materials and settings are inaccessible may not realize how the curriculum interacts with students' disabilities to influence their academic and postschool outcomes. The lack of awareness that time is a factor in hidden curricula contributes to reproducing failed learners, especially when educators focus on their impairments rather than the barriers they face in the education system.

Time as a hidden curriculum enables learners without disabilities to work within the schooling framework, which again allows them to perform well and to maintain dominance in school and later adulthood. It allows divisionary and exclusionary practices that make education systems unfriendly to learners with mobility, speech, and visual disabilities. Even though time drives cultural practices of schooling (e.g., teachers' low expectations for "slow" learners) that divides "normal" children from "abnormal" children, it is never explicitly questioned by stakeholders in education, thus turning it into a weaponized tool by which some learners are empowered and others are disempowered. Teaching within a prescribed time framework allows teachers, whether inadvertently or not, to compare the abilities of learners with and without disabilities and to pass judgment about their worthiness in the school community and in larger society. These judgments influence the teachers' commitment to each group. It questions the ability of learners with disabilities and determines their access to learning opportunities. Time as a hidden curriculum hinders the authentic learning that all students need to compete in this meritocratic society, and in the process, produces winners (students without disabilities) and losers (students with disabilities), the latter of which is condemned to the margins of society for their own impairments. Educators then become agents that advance abled-disabled binaries and sanction educational practices that hierarchize learners based on ability (Kafer, 2013; McRuer, 2017; Samuels, 2017).

Addressing issues of time as a hidden curriculum is necessary for successful schooling of students with disabilities. Individualizing accommodation guided by the universal design of learning principles (Karlsone, 2015), differentiated instruction strategies (Lawrence-Brown, 2020), and culturally relevant pedagogy tenets 
(Grassi \& Barker, 2010) is key to addressing the learning needs of learners with mobility, speech, and visual disabilities.

Participation and belonging of students with mobility issues are influenced by time and space. Time and space influence differently learners with disabilities' educational, physical, mental, social, cultural, and linguistic domains than their peers (Kang, 2019). This is because mobility contributes to students' independence, whereas restricted movement impedes daily activities, limits experience, and lowers quality of life (Hayasaki, 2017). Mobility issues significantly compromise an individual's movement and limit their development of social, cognitive, and adaptive behaviors and skills. Environmental barriers exacerbate impairments, often making students frustrated and reluctant to interact with peers or participate in learning activities. Considering the array of causal factors of physical disabilities and their impacts, unempathetic educators can blame learners' impairments when they observe limited class participation and low academic performance. However, knowledge of these traits can inform teachers' best practices, allowing empathetic educators to promote the inclusion, belonging, and successful schooling of learners with mobility disabilities. Titchkosky (2011) explores interactions of space and belonging in higher education, arguing that physical and digital accessibility are not enough to address inclusion issues. The author recommends gearing inclusive practices toward empowering individuals with disabilities within the university community - the same is applicable at the P-12 school level. Therefore, students with mobility issues need changes of the environment, curriculum plan, or tools to enable them gain access and participate in learning (Duhaney \& Duhaney, 2000). Their overall quality life is enhanced with the assistive devices (e.g., mobility aids, ramps, elevators) or educational technology (e.g., digital books, videos) and extra time for activities (e.g., tests, or changing classes) and assistance with learning activities (e.g., writing, reading, laboratory experiments) and daily living activities (e.g., taking medication, bathing, dressing, eating) or support with functional skills (e.g., ambulation, mobility, transportation services) (Kang, 2019).

Similarly, people who stutter can experience a diminished quality of life and adverse psychosocial experiences due to societal judgments (Boyle, 2018). For example, when it comes to students who stutters, listeners' attitudes and judgments, regardless of whether they are stated directly, send indirect messages about how they feel about a phenomenon (Crowe \& Walton, 1981; Daniels et al., 2012). Crichton-Smith (2002) found that students are traumatized when teachers view their stuttering as an individual problem and a barrier to whole class learning. Since student teachers and certified teachers often lack appropriate knowledge about students who stutter (Panico et al., 2018), providing teachers more knowledge about stuttering and ways to best accommodate students who stutter in class can help create a supportive learning environment (Adriaensens \& Struyf, 2016; Arnold et., 2015). Educators should provide ample time for activities such as selfintroduction, oral reading assignments, classroom presentations, answering questions, and using the phonethey should be sensitive to students' needs and make classrooms more comfortable by allowing time for all students regardless of whether or not they stutter. The degree to which one defines stuttering as an impairment or disability depends upon the person who stutters - many see stuttering not as shameful but as a culture of disability pride and empowerment (Boyle et al., 2016). So, discussing educator and peer attitudes is important in understanding how people who stutter experience challenges in school settings and challenges with time. Personal perspectives of people who stutter related to their school experiences in the context of time as a hidden curriculum can guide educators in instituting appropriate measures that support inclusion of such students.

Likewise, blind students experience low quality of life in unsafe environments. Because vision is so important to sighted people, blindness is often understood as a severe disability whose complicated effects arise unpredictably and pervade every aspect of a person's personal, educational, and social life (Teutsch et al., 2016). Thus, it seems difficult to determine "what to do" when a blind student enters an inclusive classroom. But despite the many consequences of blindness, the overall situation is less complex than might be assumed. The easiest, most accurate way of thinking about blindness is as lacking information rather than as lacking vision. This perspective conveys the essence of a blind student's needed accommodations, helping curtail the emotion, exaggeration, and hysteria sometimes associated with blindness. From this perspective, it is easier to assess activities and decide how a blind student can participate in them. For example, camp counsellors might feel that riding atop a wagon of logs destined for the evening campfire is impossible (or inadvisable) for a blind camper, fearing the learner will fall or be injured. If we ask - "Is the blind student fine doing this?" - we might have trouble finding the answer. But if we ask - "What information does the student 
need to participate?" - the answer becomes clearer. The student must know where to climb onto the wagon, how the logs are arranged, where the edges of the pile are, and how the wagon will be pulled so she or he can predict the changes that will occur when the wagon begins moving. This is what sighted students know immediately by looking, and given this information, the blind student can participate safely.

Note that a considerable amount of the visual information we absorb is redundantly coded -in other words, visually transmitted information is often available through other senses (Hutmacher, 2019). Blind students may not see a teacher approaching, but other things being equal, they will notice the teacher is not talking to anyone else, will consider the context (whether their hands are raised, whether it has been some time since they have interacted with the teacher), and they will hear the footsteps moving toward them. Because sighted people over-rely on vision, the amount of information available to the blind learner is often underestimated. Still, some information is primarily (if not exclusively) carried by vision - this is where accommodation is most necessary. For example, blind students may be unable to read standard print on the chalkboard or in textbooks. This may require relocating students to the front of the class, providing magnification, or providing Braille or audio texts so students have non-visual access. Blind students may need orientation toward the classroom, school building, and playground layout so they can move independently, often using a white cane to investigate obstacles. Teachers who rely on writing on the board must learn to speak aloud as they write, which will benefit all students. For other classroom activities - such as games, pair work, or interaction with audio-visual material-information must be given to the student verbally, in large print, in Braille, or in a combination of these. These types of accommodations enhance blind students' functionality and academic performance.

\section{CONCLUSION}

Time as an element in schooling is embedded in the curriculum and influences unmentioned practices that impact the education of learners with mobility, speech, and visual disabilities. A great deal of exclusion experienced by students with mobility, speech, and visual disabilities is embedded in time-related practices that schools cherish as determinants of intelligence and success. Often, time contributes to the bias against learners and creates social stratification-those who cannot move at a societally established rate are left behind, whereas those who can maintain or speed or accelerate past the expected norm are valued and rewarded. Students with mobility, speech, and visual disabilities who fail to meet the established threshold are quickly diagnosed as unfit and condemned as social misfits. This degradation becomes a way of sanctioning their low school performance and qualifying their low rank in society, leading to a lower quality of life. It is vital for students with mobility, speech, and visual disabilities, their nondisabled peers, and educators to know that time as a hidden curriculum is a learning barrier that may be enacted intentionally or unintentionally and that may be conspicuous or inconspicuous.

Labelling and stereotyping students with disabilities can make school life difficult. Considering the negative impact of such un/intentional teacher actions, creating social situations that allows students with disabilities be comfortable and develop coping strategies is imperative. Therefore, addressing time issues in the curriculum is vital in taming negative classroom experiences endured by learners with disabilities. As change agents, educators should use their status to manipulate time and curriculum to support students' learning and inclusion. Most students and teachers are very understanding, sympathetic, and supportive of students with disabilities; however, sometimes they do not know how to appropriately support them. Creating safe spaces would nurture reciprocal relationships and enable students to share their concerns about time and curriculum and allow educators to institute appropriate interventions. Regarding students with mobility issues, educators should be cognizant of learning environment relative to their abilities as well as the influence of distance and time on learning. Regarding students who stutter, educators should be aware of how time influences speech-related activities. Regarding students with visual impairment and blind students, educators should also be aware of their learning needs to ensure that lack of access to Braille or appropriate lighting, for example, does not interfere with the learning process and activities.

\section{Limitations}

Though this study provides substantive solutions to problems of time as a hidden curriculum, the three case scenarios on learners with mobility, speech, and visual disabilities are informed by authors' personal experiences hence cannot be generalized. Therefore, future research should focus on P-12 children with disabilities and time as a hidden curriculum in the era of remote teaching and learning. 


\section{REFERENCES}

Adriaensens, S., \& Struyf, E. (2016). Secondary school teachers' beliefs, attitudes, and reactions to stuttering. Language, Speech, and Hearing Services in Schools, 47(2), 135-147. https://doi.org/10.1044/2016 lshss-15$\underline{0019}$

Arnold, H.S., Li, J., \& Goltl, K. (2015). Beliefs of teachers versus non-teachers about people who stutter. Journal of Fluency Disorders, 43, 28-39. https://doi.org/10.1016/j.jfludis.2014.12.001

Berg, L. A., Jirikowic, T., Haerling, K., \& MacDonald, G. (2017). Navigating the hidden curriculum of higher education for postsecondary students with intellectual disabilities. The American Journal of Occupational Therapy, 71(3), 1-9. https://doi.org/10.5014/ajot.2017.024703

Bernard, H. R. (2017-2002). Research methods in anthropology: Qualitative and quantitative approaches (6 ${ }^{\text {th }}$ ed.). Rowman \& Littlefield Publishers.

Black, L. I. (2017). QuickStats: Percentage of children aged 6-17 years who wear glasses or contact lenses, by sex and age group - National Health Interview Survey, 2016. Morbidity and Mortality Weekly Report, 66, 917. http://dx.doi.org/10.15585/mmwr.mm6634a7

Bottge, B. A., Ma, X., Gassaway, L. J., Jones, M., \& Gravil, M. (2020). Effects of formative assessment strategies on the fractions computation skills of students with disabilities. Remedial and Special Education, 1-11. https://doi.org/10.1177/0741932520942954

Bottini, R., Crepaldi, D., Casasanto, D., Crollen, V., \& Collignon, O. (2015). Space and time in the sighted and blind. Cognition, 141, 67-72. https://doi.org/10.1016/j.cognition.2015.04.004

Boyle, M. P. (2018). Enacted stigma and felt stigma experienced by adults who stutter. Journal of Communication Disorders, 73, 50-61. https://doi.org/10.1016/j.jcomdis.2018.03.004

Boyle, M. P, Daniels, D. E., Hughes, C. D., \& Buhr, A. P. (2016). Considering disability culture for culturally competent interactions with individuals who stutter. Contemporary Issues in Communication Science and Disorders, 43(Spring), 11-22. https://doi.org/10.1044/cicsd 43 s 11

Bunnag, A. (2017). The concept of time in philosophy: A comparative study between Theravada Buddhist and Henri Bergson's concept of time from Thai philosophers' perspectives. Kasetsart Journal of Social Sciences, 40(1), 1-7. https://doi.org/10.1016/j.kjss.2017.07.007

Burnham, D. \& Staffordshire University. (2006). Gottfried Wilhelm Leibniz (1646-1716) Metaphysics - 7. Space, time, and indiscernibles. In J. Fieser \& B. Dowden (Eds.), The Internet encyclopedia of philosophy. https://www.iep.utm.edu/eds/

Carroll, S. M. (2010). From eternity to here: The quest for the ultimate theory of Time (54-55). Dutton.

Castillo, J. M., Wolgemuth, J. R., Barclay, C., Mattison, A., Tan, S. Y., Sabnis, S., Brundage, A., \& Marshall, L. (2016). A qualitative study of facilitators and barriers related to comprehensive and integrated school psychological services. Psychology in the Schools, 53(6), 641-658. https://doi.org/10.1002/pits.21932

Considine, D. M. \& Considine, G. D. (1985). Process instruments and controls handbook (3 ed.) (18-61). McGrawHill.

Corbin, J., \& Strauss, A. (2008). Basics of qualitative research: Techniques and procedures for developing grounded theory ( $3 r d E d$.). SAGE Publications, Inc.

Crichton-Smith, I. (2002). Communicating in the real-world: Accounts from people who stammer. Journal of Fluency Disorders, 27(4), 333-351. https://doi.org/10.1016/s0094-730x(02)00161-4

Crowe, T.A., \& Walton, J.H. (1981). Teacher attitudes toward stuttering. Journal of Fluency Disorders, 6(2), 163174. https://doi.org/10.1016/0094-730x(81)90013-9

Danforth, S. (2017). Becoming a great inclusive educator (2nd Ed.). Peter Lang Inc.

Daniels, D. E., Gabel, R. M., \& Hughes, S. (2012). Recounting the K-12 school experiences of adults who stutter: A qualitative analysis. Journal of Fluency Disorders, 37(2), 71-82. https://doi.org/10.1016/j.jfludis.2011.12.001

Davis, S., Howell, P., \& Cooke, F. (2002). Sociodynamic relationships between children who stutter and their non-stuttering classmates. Journal of Child Psychology and Psychiatry, 43(7), 939-947. https://doi.org/10.1111/1469-7610.00093

Duhaney, D. C., \& Duhaney, L. M. G. (2000). Assistive technology: Meeting the needs of learners with disabilities. International Journal of Instructional Media, 27(4), 393-401. https://eric.ed.gov/?id=EJ623542

Elias, N. (1992). Time: An essay. Blackwell Publishers.

Fialka, J. (2016). What matters: Reflections on disability, community \& love. Inclusion Press 
Fogle, P.T. (2019). Essentials of communication sciences and disorders (2 ${ }^{\text {nd }}$ Ed.). Jones and Bartlett Learning.

Franck, A.L., Jackson, R.A., Pimentel, J.T., \& Greenwood, G.S. (2003). School-age children's perceptions of a person who stutters. Journal of Fluency Disorders, 28(1), 1-15. https://doi.org/10.1016/s0094$\underline{730 \times(03) 00002-0}$

Gabbert, C. (2012). Common types and characteristics of visual impairments. Retrieved September 20, 2019 from https://www.brighthubeducation.com/special-ed-visual-impairments/35103-common-types-ofvisual-impairment-in-students/

Giroux, H. A., \& Penna, A. N. (1979). Social education in the classroom: The dynamics of the hidden curriculum. Theory $\mathcal{E}$ Research in Social Education, 7(1), 21-42. https://doi.org/10.1080/00933104.1979.10506048

Hugh-Jones, S., \& Smith, P. K. (1999). Self-reports of short- and long-term effects of bullying on children who stammer. British Journal of Educational Psychology, 69(2), 141-158. https://doi.org/10.1348/000709999157626

Hutmacher, F. (2019). Why is there so much more research on vision than on any other sensory modality? Frontiers in psychology, 10, 2246. https://doi.org/10.3389/fpsyg.2019.02246

Ivey, D. G. \& Hume, J.N.P. (1974). Physics. Ronald Press.

Johnson, L., \& Lawson, H. (2006). Teachers of visually impaired students as providers of related services? "Supportive services" versus "specially designed instruction." Journal of Visual Impairment \& Blindness, 100(10), 595-596. https://doi.org/10.1177/0145482x0610001008

Kafer, A. (2013). Feminist, queer, crip. Indiana University Press.

Kang, P. B. (2019). Muscles, bones, and nerves. In M. L. Batshaw, N. J. Roizen, \& L. Pellegrino (Eds.), Children with disabilities (213-229). Paul H. Brookes Publishing Co.

Kant, I. (2004). The Critique of pure reason (2nd Ed.). (J. M. D. Meiklejohn, Trans.). eBooks@Adelaide. (Original work published 1787).

Karlsone, I. (2015). The Principles of universal design for learning implementation in design study process. https://doi.org/10.15405/epsbs.2015.01.12

Klompas, M., \& Ross, E. (2004). Life experiences of people who stutter, and the perceived impact of stuttering on quality of life: Personal accounts of South African individuals. Journal of Fluency Disorders, 29(4), 275-305. https://doi.org/10.1016/j.jfludis.2004.10.001

Lass, N.J., Ruscello, D.M., Pannbacker, M., Schmitt, J.F., Kiser, A.M., Mussa, A.M., \& Lockart, P. (1994). School administrators' perceptions of people who stutter. Language, Speech, and Hearing Services in Schools, 25(2), 90-93. https://doi.org/10.1044/0161-1461.2502.90

Lass, N.J., Ruscello, D.M., Schmitt, J.F., Pannbacker, M.D., Orlando, M.B., Dean, K.A., Ruziska, J.C., \& Bradshaw, K.H. (1992). Teachers' perceptions of stutterers. Language, Speech, and Hearing Services in Schools, 24(2), 108-109. https://doi.org/10.1044/0161-1461.2402.108b

Lawrence-Brown, D. (2020). Differentiated instruction and inclusive schooling. Oxford Research Encyclopedia of Education. https://doi.org/10.1093/acrefore/9780190264093.013.1223

Le Poidevin, R. (2004). The experience and perception of time. In Edward N. Zalta (Ed.), The Stanford Encyclopedia of Philosophy. Retrieved July 2, 2019 from https://plato.stanford.edu/cgibin/encyclopedia/archinfo.cgi?entry=time-experience

Lennie, P. \& Van Hemel, S. B. (Eds.). (2002). Visual impairments: Determining eligibility for social security benefits. National Academy Press.

Luckham, D. \& Schulte, R. (2011). Event processing glossary-Version 2.0. Real time intelligence \& complex event processing. Retrieved July 3, 2019 from http://www.complexevents.com/2011/08/23/event-processingglossary-version-2/

McLean, S., \& Dixit, J. (2018). The power of positive thinking: A hidden curriculum for precarious times. Adult Education Quarterly: A Journal of Research and Theory, 68(4), 280-296. https://doi.org/10.1177/0741713618777817

McRuer, R. (2017). Crip times: Disability, globalization, and resistance. NYU Press.

Grassi, E. A., \& Barker, H. B. (2010). Culturally and linguistically diverse exceptional students: Strategies for teaching and assessment. SAGE Publications, Inc.

Nelms, T. P. (1991). Has the curriculum revolution revolutionized the definition of curriculum? Journal of Nursing Education, 30(1), 5-8. https://doi.org/10.3928/0148-4834-19910101-04 
Nordquist, R. (Updated January 20, 2019). Definition and examples of narratives in writing. Retrieved July 3 , 2019 from https://www.thoughtco.com/narrative-composition-term-1691417

Núñez, R., Cooperrider, K., Doan, D. \& Wassmann, J. (July 1, 2012). Contours of time: Topographic construals of past, present, and future in the Yupno Valley of Papua New Guinea. Cognition, 124(1), 25-35. https://doi.org/10.1016/j.cognition.2012.03.007

Palinkas, L. A., Aarons, G. A., Horwitz, S. M., Chamberlain, P., Hurlburt, M., Landsverk, J. (2011). Mixed method designs in implementation research. Adm Policy Ment Health, 38, 44-53. https://doi.org/10.1007/s10488-010-0314-z

Panico, J., Daniels, D.E., Hughes, S., Smith, R.E., \& Zelenak, J. (2018). Comparing perceptions of student teachers and regular education teachers toward students who stutter: A mixed-methods approach. Speech, Language, and Hearing, 21(4), 245-255. https://doi.org/10.1080/2050571x.2017.1391425

Patton, M. Q. (2014). Qualitative research $\mathcal{E}$ evaluation methods: Integrating theory and practice ( th $^{\text {th }} \mathrm{ed}$.). Sage Publications.

Piasecki, D. J. (2011). Inventory accuracy glossary. AccuracyBook.com (OPS Publishing). Retrieved July 3, 2019 from https://www.accuracybook.com/glossary.html.

Ray, P. L., Cox, A. P., Jensen, M., Allen, T., Duncan, W., \& Diehl, A. D. (2016). Representing vision and blindness. Journal of Biomedical Semantics, 7(1), 1-12. https://doi.org/10.1186/s13326-016-0058-0

Russell, D. W., Altmaier, E., \& Van Velzen, D. (1987). Job-related stress, social support, and burnout among classroom teachers. Journal of Applied Psychology, 72(2), 269-274. https://doi.org/10.1037/0021$\underline{9010.72 .2 .269}$

Samuels, E. (2017). Six ways of looking at crip time. Disability Studies Quarterly, 17(3). https://doi.org/10.18061/dsq.v37i3.5824

Silverman, F. H. \& Marik, J. H. (1993). Teachers' perceptions of stutterers. Language, Speech, and Hearing Services in Schools, 24(2), 108. https://doi.org/10.1044/0161-1461.2402.108a

Silvestri, N. J. (Ed.). (2018). Neuromuscular disorders: A symptoms and signs approach to differential diagnosis and treatment. Demos Medical Publishing.

Spradley, J. P. (2016-1979). The ethnographic interview (Reissue ed.). Waveland Press, Inc.

St. Augustine (2012). The Confessions of Saint Augustine. (E. B. Pusey, Trans.). Simon \& Brown.

Teddlie, C., \& Tashakkori, A. (2010-2003). Major issues and controversies in the use of mixed methods in the social and behavioral sciences. In A. Tashakkori \& C. Teddlie (Eds.) SAGE Handbook of Mixed Methods in Social \& Behavioral Research (2nd ed.) (pp. 3-50). SAGE Publications, Inc.

Teutsch, S.M., McCoy, M.A., Woodbury, R. B., \& Welp, A. (Eds.) (2016). Making eye health a population health imperative: Vision for tomorrow. National Academies Press.

The Vision Council (2015). Percentage of American adults using any form of vision correction with gender and age groups. Vision Watch.

Titchkosky, T. (2011). The question of access: Disability, space, meaning. University of Toronto Press U.S. Department of Education, Office of Special Education Programs, Individuals with Disabilities Education Act (IDEA) database. Retrieved from https://www2.ed.gov/programs/osepidea/618data/state-level-data-files/index.html\#bcc

Yeakle, M.K., \& Cooper, E.B. (1986). Teacher perceptions of stuttering. Journal of Fluency Disorders, 11(4), 345359. https://doi.org/10.1016/0094-730x(86)90022-7

Zeigler, K. (2008). Getting organized at work: 24 lessons for setting goals, establishing priorities, and managing your time (mighty manager). McGraw-Hill Education. 